\title{
Iron (Fe) Nutrition of Plants ${ }^{1}$
}

\author{
George Hochmuth ${ }^{2}$
}

\section{Introduction}

Iron is one of 16 essential elements for plant growth and reproduction (some scientists also consider nickel to be essential, making 17 in total). Iron $(\mathrm{Fe})$ is one of the most abundant elements on the planet. In 1844, Eusebe Gris showed that certain chlorosis in plants could be reversed by treating roots and leaves with iron solutions. Iron is a micronutrient and is required by plants in small amounts. Most annual plants have a requirement for $\mathrm{Fe}$ on the order of 1 to $1.5 \mathrm{lb}$ Fe per acre, compared with nitrogen $(\mathrm{N})$ at 80 to $200 \mathrm{lb}$ per acre. This publication provides information on plant nutrition and soil fertility for agricultural and urban plant production and management practitioners. The information should provide a detailed basic understanding of soil science and plant physiology for diagnosing and correcting Fe problems in plants and soils. The audience for this publication includes county agents, crop consultants, environmental managers, and fertilizer and lawn care specialists.

\section{Forms of Fe in the Natural Environment}

The most abundant form of Fe in soils is ferric oxide $\left(\mathrm{Fe}_{2} \mathrm{O}_{3}\right)$ or hematite, which is extremely insoluble and imparts a red color to the soil. The oxide form is commonly hydrated. In aerobic soils, the oxide, hydroxide, and phosphate forms control the concentration of Fe in solution and its availability to plants. In typical aerated plant production systems of acceptable reaction $(\mathrm{pH})$ of $+/-6.0$, the concentrations of ferric $\left(\mathrm{Fe}^{++}\right)$and ferrous $\mathrm{Fe}^{++}$iron are on the order of $10^{-15}$ molar (very low concentration). As $\mathrm{pH}$ increases by one unit, activity of $\mathrm{Fe}^{+++}$decreases by 1000 -fold due to the formation of insoluble $\mathrm{Fe}^{+++}$hydroxide. Under reducing conditions-addition of $\mathrm{H}^{+}$or other reductants-Fe solubility increases. Under such situations, Fe can be adsorbed on soil as an exchangeable ion.

In certain soil situations, carbonate or sulfide compounds may form with Fe. Commonly in waterlogged situations, ferric iron is reduced to the ferrous state. If sulfates also are abundant in the soil, these become oxygen sources for bacteria and black-colored ferrous sulfide is formed

Where organic matter is present in soils, Fe may be present in its reduced state as $\mathrm{Fe}^{++}$in the soil solution or adsorbed onto soil particle surfaces. Organic matter in soils plays a major role in the availability of Fe to plants. Biochemical compounds or organic acids (aliphatic acids or amino acids) and complex polymers (humic and fulvic acids) can form soluble complexes with $\mathrm{Fe}$, or act as chelating agents and thereby increase Fe availability to plants (chelating agents are organic compounds that complex with Fe and help hold $\mathrm{Fe}$ in more soluble forms).

\section{Function of Fe in the Plant}

Although required by plants in small amounts, Fe is involved in many important compounds and physiological processes in plants. Iron is involved in the manufacturing process of chlorophyll, and it is required for certain enzyme functions. Fe's involvement in chlorophyll synthesis is the reason for the chlorosis (yellowing) associated with $\mathrm{Fe}$

1. This document is SL353, one of a series of the Soil and Water Science Department, Florida Cooperative Extension Service, Institute of Food and Agricultural Sciences, University of Florida. Original publication date, August 2011. Visit the EDIS website at http://edis.ifas.ufl.edu

2. George Hochmuth, professor, Department of Soil and Water Science; Florida Cooperative Extension Service, Institute of Food and Agricultural Sciences, University of Florida, Gainesville, FL 32611. 
deficiency. Iron is found in the iron-containing (heme) proteins in plants, examples of which are the cytochromes. Cytochromes are found in the electron transfer systems in chloroplasts and mitochondria. Iron is also associated with certain non-heme proteins such as ferredoxin.

\section{Fe Uptake and Transport}

Iron arrives in the vicinity of the root as various chemical compounds or organic complexes, rarely as elemental Fe. Iron in the soil solution can be moved to the plant root as a component in the bulk soil pore solution moving toward the root as water is taken into the plant to replace that lost by transpiration or used in growth processes. Iron also can move to the root by diffusion from a region of high concentration to a lower one (at the root surface as Fe is taken up by the plant). Roots also can intercept Fe compounds in the soil as the roots grow and expand into additional soil volume. Root density and extension are very important factors in the plant's ability to obtain Fe.

Iron uptake by the plant is not as simple as with other essential elements. Iron is taken up by plant roots in greatest amounts in the zone of the root between cell elongation and maturation, about 1 to $4 \mathrm{~cm}$ behind the root tip. Uptake of Fe by the plant is an active process, that is, energy is expended by the plant to take in Fe. Iron uptake is dependent on the plant's ability to reduce $\mathrm{Fe}^{+++}$to $\mathrm{Fe}^{++}$ and remove it from the complex or chelating compound. Research evidence shows this reduction occurs at the cell surface and that electrons from within the cell are used. The same 1 - to $4-\mathrm{cm}$ area behind the root tip where most Fe is absorbed also is the area of the root where most protons and reductants are released. The chelated Fe in the soil solution moves to the root by mass flow or by diffusion. At the root, Fe is reduced and removed from the chelating molecule and moved across the cell membrane. Iron uptake can be interfered with by other cations in the soil solution such as manganese $(\mathrm{Mn})$ and calcium $(\mathrm{Ca})$.

In grasses, phytosiderophores (organic acids) are synthesized by the plant root and released into the rhizosphere, where they form complexes with Fe. The phytosiderophereplus Fe complex is moved across the membrane in the root.

Iron is absorbed into the rhizodermal (epidermal) cells and endodermal cells in the root (Figure 1). From the endodermis, $\mathrm{Fe}$ is loaded into the pericycle cells and then to the xylem. Most of the Fe transported to the shoots ends up in the shoot apoplast. From here it can be moved across the cell plasmalemma and into the cytoplasm and into organelles.
Movement of Fe from one part of the shoot, particularly senescent leaves, to other shoot parts via the phloem does occur, however most scientists believe Fe is not easily re-translocated in plant shoots.

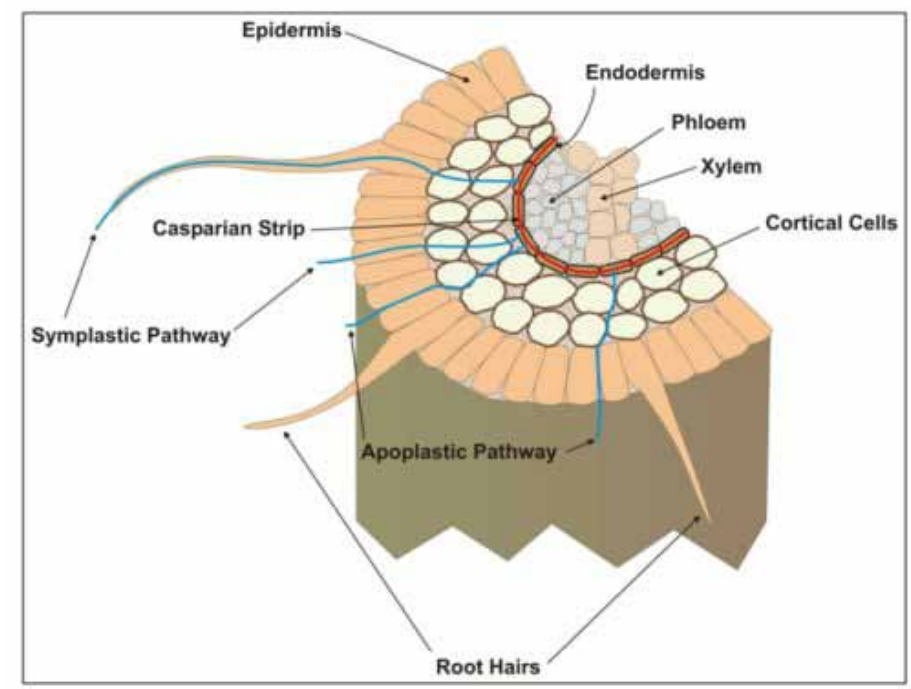

Figure 1. Root morphology.

\section{Fe Transport}

Iron is maintained in solution in the cell exterior environment by organic acids. Researchers then predicted that Fe should be translocated inside the plant by organic acids. This result was found to be true. Once Fe is moved across the membrane it is complexed with organic acids in the cell, which prevents Fe precipitation with phosphate or hydroxide. The most important organic acid in this process is citrate.

Iron in the plant is mostly in the ferric form, and much of the Fe is found in the plastids. Another significant pool of Fe is found in the apoplast (extracellular area) of the older part of the root, but it is thought this pool plays little role in supplying Fe at the onset of deficiency in the shoots. Iron is relatively immobile once incorporated in compounds in the upper parts of the plants. Re-translocation of Fe from one shoot tissue or plant part to another is negligible. Therefore, Fe deficiency symptoms show up first in the youngest leaves. These young leaves show yellowing, sometimes referred to as "iron chlorosis." Soils with a basic reaction ( $>$ pH 7.2) often result in Fe deficiency because under these elevated $\mathrm{pH}$ conditions Fe is largely in the oxide and unavailable form. Acidic soils also can lead to Fe deficiency, likely due to manganese competition with $\mathrm{Fe}$ uptake. High $\mathrm{Ca}$ and carbonate concentrations in soil from over-liming also can lead to Fe deficiencies ("lime-induced Fe chlorosis") due to the high $\mathrm{pH}$ (more insoluble Fe) and 
competition of Ca with Fe uptake by the root. For the same reason, continual use of irrigation water with high concentrations of carbonates can lead to chlorosis.

\section{Soil Testing for Fe}

Several soil testing methods have been tried for predicting crop needs for Fe fertilizers. Of several extractants tested for exchangeable $\mathrm{Fe}$, sodium acetate $\left(\mathrm{NaC}_{2} \mathrm{H}_{3} \mathrm{O}_{2}\right.$ and $\mathrm{ED}$ DHA-ethylenediamine-N,N'-bis(2-hydroxyphenylacetic acid) - correlated best with plant growth. Chelating extractants, including EDDHA, DTPA (diethylene triamine pentaacetic acid), and mixtures such as DTPA plus $\mathrm{CaCl}_{2}$ (calcium chloride) also have been tested and have been somewhat useful. The universal extractant, Mehlich-3, has been used in several states as an extractant. Iron availability is largely dependent on many soil and environmental factors, such as soil $\mathrm{pH}$ and bicarbonate concentration, in addition to the extractable amount of Fe; therefore, it is improbable there will be a very reliable soil test method until these factors are better understood. It might be more useful to have information on soil $\mathrm{pH}$ and bicarbonate content of the soil sample and relate that information to $\mathrm{Fe}$ availability.

\section{Plant Tissue Fe Content}

Plant tissue analyses for Fe are problematic to interpret unless the leaves have been rinsed in dilute acid or detergent. This problem arises because $\mathrm{Fe}$ is ubiquitous in dust and can be a contaminant on the surface of plant leaves. Most tests rely on analysis of young leaves from the upper parts or extremities of the plants. Young leaves are chosen because Fe, once deposited in the leaf tissue, is not readily re-translocated; hence, older leaves of deficient plants may have a relatively high concentration of Fe. Young leaves of most plants should contain about 50 parts per million (ppm) Fe, or greater on a dry weight basis (Table 1). Deficient plants will have leaves with less than $30 \mathrm{ppm} \mathrm{Fe}$ and will likely exhibit the chlorosis typical of Fe-deficient plants.

Iron deficiency symptoms generally consist of a yellowing or chlorosis of the youngest leaves. Often there is an interveinal appearance where the veins remain green for a time as the deficiency progresses. Several nutrient deficiencies lead to chlorosis of plants. In turfgrass, Fe deficiency is sometimes confused with nitrogen deficiency. Iron deficiency symptoms manifest themselves in the younger leaves due to the relative immobility of $\mathrm{Fe}$ in the plants. Nitrogen deficiency, however, is manifest first in the older leaves because $\mathrm{N}$ can be mobilized from the older leaves to satisfy the needs in the upper plant. Iron deficiency in turfgrass is typically in spots or patches, whereas $\mathrm{N}$ deficiency is more broadly spread in the lawn. Spraying Fe will turn Fe-deficient leaves green because Fe is now available to manufacture more chlorophyll, the green color in plants. Other nutrients with chlorotic deficiency symptoms are magnesium $(\mathrm{Mg})$ and sulfur $(\mathrm{S})$. The symptoms appear similar to the untrained eye, so it is important to correctly diagnose the problem (ruling out other factors that can lead to chlorotic plants, such as diseases, nematodes, flooding, and herbicide damage) before taking corrective action.

Iron deficiency symptoms for monocot and dicot plants are shown in Figures 2-5. In all plant species, the main symptom of Fe deficiency is chlorosis in young leaves. Plants have two means, called "strategies," for dealing with Fe deficiency. Most plants, except the grasses (graminaceous species), use Strategy 1, in which root extension is restricted, and root hair production is increased. These morphological changes are associated with the production of specialized transfer cells that excrete protons and reductants to acidify the soil environment and enhance Fe uptake. Grasses employ Strategy 2, in which, under Fe deficiency, the roots secrete chelating agents (phytosiderophores) to help scavenge $\mathrm{Fe}$, and these complexes are taken across the plasma membrane (plasmalemma) by a transporter.

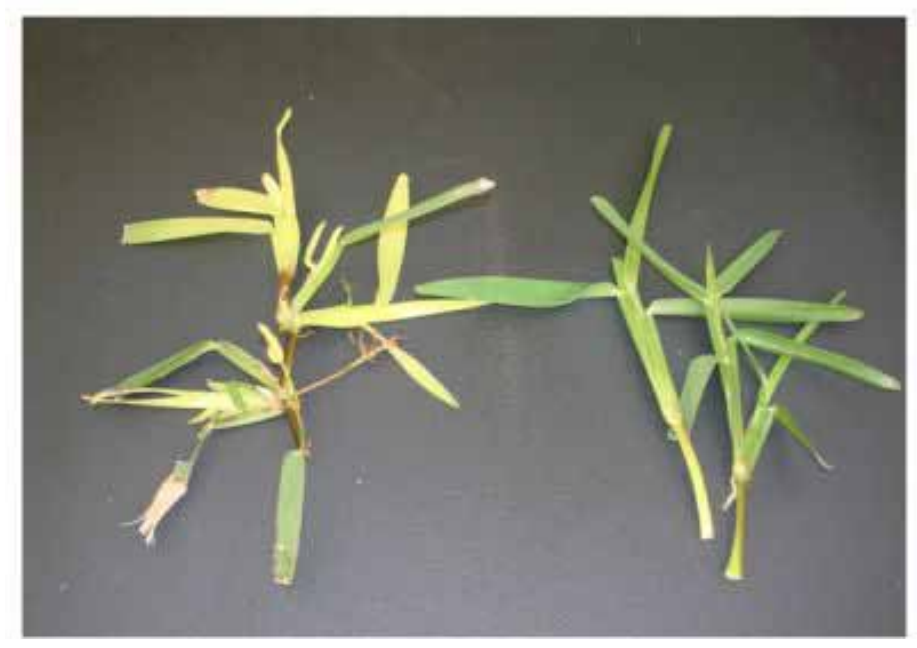

Figure 2. Iron deficiency in St Augustinegrass.

Credits: G. Hochmuth.

Iron toxicity has not been reported under most aerobic plant production systems; however, it can be a problem ("bronzing") in waterlogged systems of wetland rice production, where toxicity is associated with Fe concentrations of $>500 \mathrm{ppm}$ in the plant.

There are several laboratory methods for Fe determination in plant tissues, including atomic absorption and plasma 


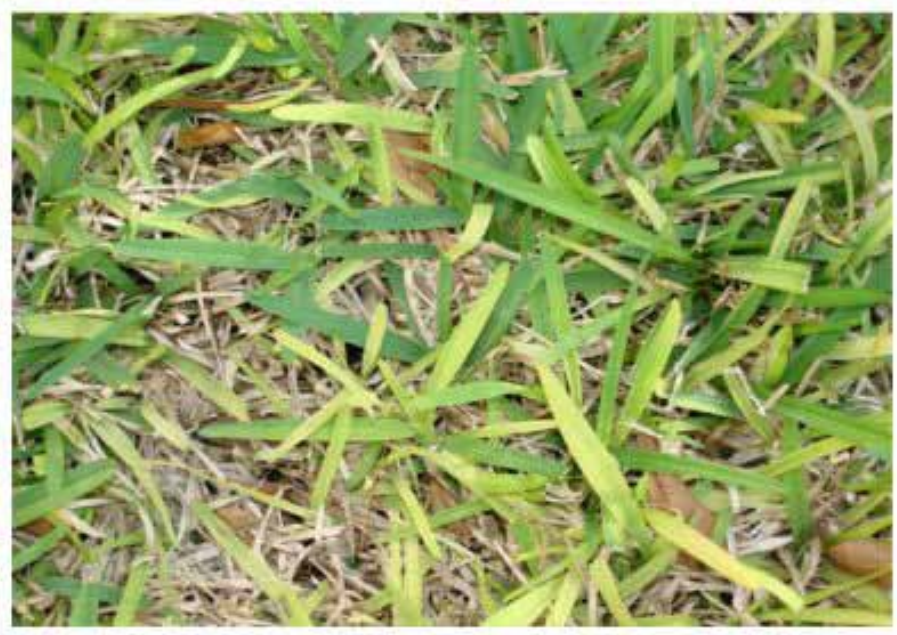

Figure 3. Yellowing of St. Augustinegrass turf under iron deficiency. Credits: G. Hochmuth.

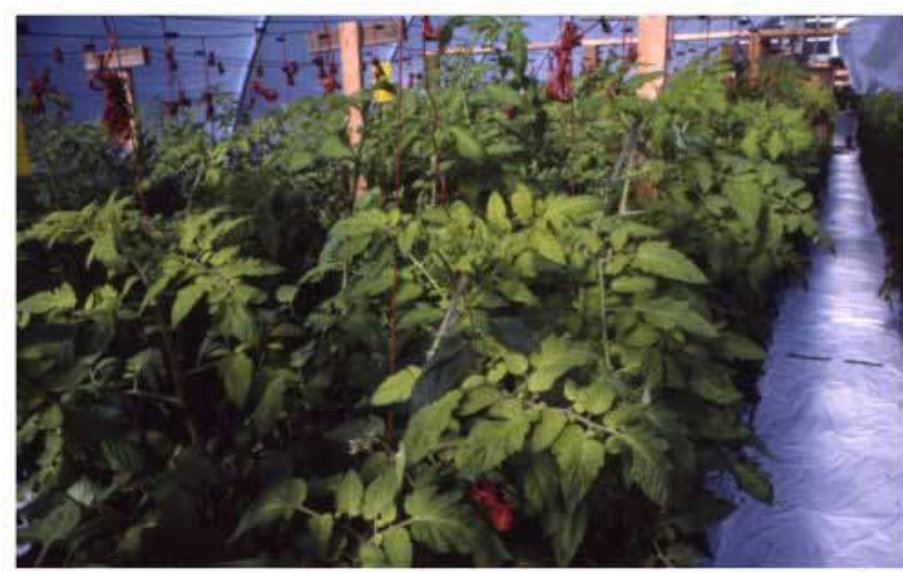

Figure 4. Yellowing of upper growth in tomato due to iron deficiency. Credits: G. Hochmuth.

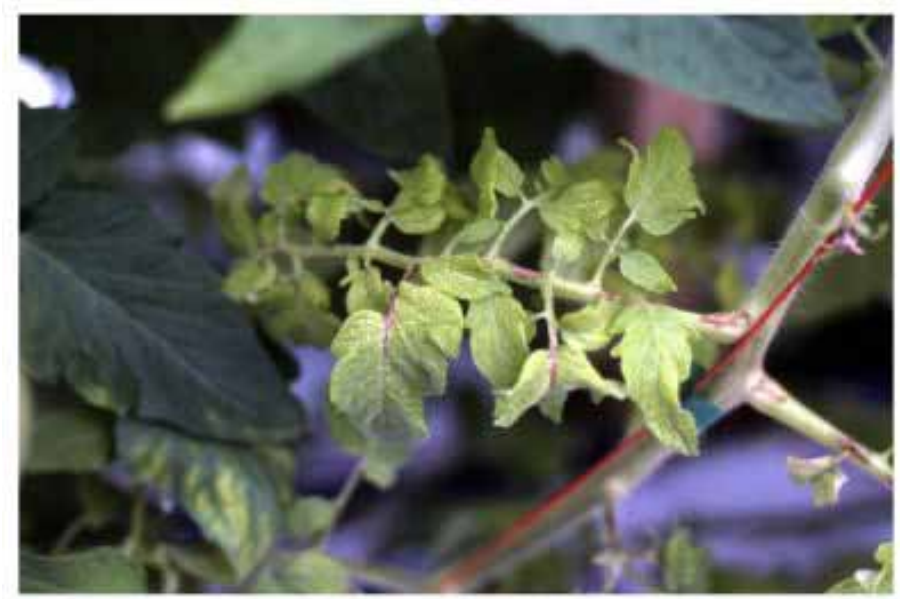

Figure 5. Progressed iron deficiency in tomato. Note brown necrotic areas of prolonged iron deficiency.

Credits: G. Hochmuth.

emission spectroscopy. Interpretation of Fe analytical results is not straightforward. A leaf may be low in Fe, but the actual Fe status of the soil may be sufficient. The deficiency may be caused by competition with $\mathrm{Fe}$ uptake by other cations in the soil, such as manganese or calcium. Another situation that can lead to Fe deficiency is copper-induced chlorosis. This deficiency may appear where copper-containing pesticides are used on a crop, e.g., citrus, tomato, or landscape plants. Low soil temperatures can reduce Fe uptake due to slower root extension and due to reduction of the metabolic activity needed to reduce $\mathrm{Fe}^{+++}$to $\mathrm{Fe}^{++}$or produce phytosiderophores. Plant root diseases that damage young roots can lead to Fe deficiency. This effect of lost roots due to a disease is illustrated well by the Take-All fungal root disease of turfgrass. Accurate interpretation and therefore correction of the problem depends on data about several factors, including presence of diseases, soil temperature, soil $\mathrm{pH}$, etc., in addition to the tissue concentration of Fe.

\section{Fe Fertilizers}

Iron can be applied as fertilizer in several forms and by several methods. Consideration must be given to the soil chemical reactions that affect Fe solubility and plant availability. Over the years many materials have been tested and used as fertilizers.

Crop response research with dry Fe fertilizer sources tends to favor the chelated forms over the inorganic forms. This preferential selection might be due to the sparingly soluble nature of the inorganic salts, such as iron oxides, and also to the rapid precipitation of Fe solubilized from these salts before the plant can absorb the Fe, especially in soils with high $\mathrm{pH}$ and bicarbonate levels. Fluid ammonium polyphosphate fertilizers were found to be effective carriers for Fe sulfates for crops grown on Fe-deficient soils, presumably because the Fe solubility was enhanced. Since Fe, a micronutrient, is required in small amounts by plants, there also is the issue of uniformity of application to the crop. Fertilizers in which the dry micronutrient salt is blended can be problematic because the small amounts of micronutrient are not uniformly mixed, and the material tends to settle out. Settling is a particular problem when bulk-blended fertilizers are bagged. Therefore the Fe needs to be distributed uniformly in the fertilizer material. Homogenized fertilizers and liquid materials are manufactured in a way to incorporate all nutrients uniformly in each fertilizer particle or in the solution.

Because of the very low concentrations of $\mathrm{Fe}^{+++}$and $\mathrm{Fe}^{++}$in soils, chelated forms of Fe fertilizers generally performed better for plant response and Fe uptake than dry iron oxides or sulfates for some crops. Not all crops respond to Fe additions, and responses have been shown to be variable. Iron chelate fertilizer effectiveness depends on soil $\mathrm{pH}$; for 
example, Fe EDTA is less stabile in highly calcareous soils. Responses to polyflavonoids and ligninsulfonates have been variable, and large amounts of the product are needed.

Foliar applications of Fe have resulted in more uniform success for correcting plant Fe deficiencies. Applying Fe directly to the leaves circumvents the problems associated with Fe application to the soil. Iron sulfates and many types of chelates have been used and are recommended in many states. For example, a typical recommendation would be a $3 \%$ solution of iron sulfate sprayed to leaf wetness. Addition of $0.1 \%$ urea to the iron sulfate solution may significantly increase iron uptake because iron is electronically charged but urea is not. Urea can facilitate Fe uptake in foliar application.

An interesting approach to managing Fe deficiency problems is to capitalize on the abundant variation in Fe uptake, transport, and utilization in plants. Some genotypes of certain plants, for example soybean, differ for their sensitivity to Fe deficiency. There is a genetic basis to this variation, so that Fe-efficient varieties could be developed that tolerate soils inherently low in iron that might otherwise not enable economic crop production. Molecular genetic approaches that take advantage of the knowledge about the physiological basis for a plant's response to Fe deficiency could play a role, for example, by increasing phytosiderophore production.

\section{Practical Take-home Lessons}

- Iron is a required plant nutrient for normal plant growth and reproduction.

- Iron is required in small amounts and is called a "micronutrient."

- Iron is a challenging plant nutrient to work with because of its reactions in the soil and its plant physiology.

- Iron is typically highly insoluble in the soil used for most plant production systems.

- Soil testing for Fe is problematic and there is no single superior procedure.

- Iron deficiency shows up as chlorosis (yellowing) in the newest plant growth because Fe is not re-mobilized in the plant from old to new leaves.

- One must understand several environmental and soil factors before interpreting plant nutrition results.
- The easiest and most effective strategy to temporarily correct Fe deficiency is with foliar sprays.

\section{Glossary:}

Aerobic: Describes an environment where there is adequate oxygen for biological activity; example is welltilled soil.

Anaerobic: Describes an environment where oxygen is lacking; only specialized microbes can live; example is water-logged soil.

Apoplast: The intercellular space outside the plasma membrane through which water and nutrients can move, in and around cells; movement within the apoplast does not require movement across the cell membrane.

Casparian strip: a glue-like material coating the outer cell walls of the endodermis, acting like protective cement and preventing apoplastic diffusion of nutrients toward the vascular cells.

Chelate: An organic molecule that reacts with certain nutrients such as Fe, holding Fe in the structure of the molecule and thereby holding Fe in solution and temporarily preventing its precipitation.

Chlorosis: The term given to the yellowing of plant tissue, typically involving loss of chlorophyll, the green pigment in plant cells.

Cytochrome: An important membrane-bound protein compound found in plant cells involved in electron transport; found in chloroplasts and mitochondria.

Cytoplasm: The bulk liquid material inside the cell membrane containing the organelles.

Endodermis: The layer of cells adjacent to the vascular tissue in a plant.

Epidermis: The outer layer of cells; the "skin" of the plant tissues. Root hairs are specialized epidermal (rhizodermal) cells in the root.

Mitochondria: Organelle that produces chemical energy through respiration.

Organelle: A cell compartment or subunit with a specialized function; examples are mitochondria and chloroplasts. 
Oxide: A chemical compound formed when elements mix with oxygen. Ferric oxide is formed when Fe mixes with oxygen.

Phytosiderophore: A type of chelating compound, often an amino acid, involved in sequestering $\mathrm{Fe}$ in grasses.

Plasmalemma: The cellular membrane that surrounds the cytoplasm.

Rhizodermis: The outer layer of cells of the roots.

Rhizosphere:The soil/air/water/microbe area just outside the root surface.

Symplast: The part of the plant tissue involving the interior of the cell membrane. Nutrients to move across cells must enter the cell membrane to be in the symplast.

\section{References}

The material above is summarized from the following sources. These sources provide literature references to the original research.

Barber, S. A. 1984. Soil nutrient bioavailability: A Mechanistic Approach. Wiley-Interscience. New York.

Barker, A. V., and D. J. Pilbeam. 2007. Handbook of plant nutrition. Taylor and Francis. New York.

Black, C. A. 1992. Soil fertility evaluation and control. Lewis Publ., London.

Bould, C., E. J. Hewitt, and P. Needham. 1983. Diagnosis of mineral disorders in plants. Vol. 1. Principles. Her Majesty's Stationary Office. London.

Carter, M. R. (ed.). 1993. Soil sampling and methods of analysis. Lewis Publ., London.

Epstein, E., and A. J. Bloom. 2005. Mineral nutrition of plants: principles and perspectives. $2^{\text {nd }} E d$. Sunderland, Mass.: Sinaur.

Jones, J. B., B. Wolf, and H. Mills. 1991. Plant analysis handbook. Micro-Macro Publ., Athens, GA.

Marschner, H. 1995. Mineral nutrition of higher plants. $2^{\text {nd }}$ ed. Academic Press. New York.
Mortvedt, J. J., P. M. Giordano, and W. L. Lindsay (eds.). 1972. Micronutrients in agriculture. Soil Science Society of America, Inc., Madison, WI.

Robb, D. A., and W. S. Pierpoint. 1983. Metals and micronutrients: Uptake and utilization by plants. Academic Press. New York.

Scaif, A., and M. Turner. 1983. Diagnosis of mineral disorders in plants. Vol. 2. Vegetables. Her majesty's Stationary Office. London.

Sprague, H. B. (ed.). 1964. Hunger signs in crops. $3^{\text {rd }}$ ed. D. McKay Co. New York.

Weir, R. G., and G. C. Cresswell. 1993. Plant Nutrient Disorders. (3). Vegetable crops. Inkata Press. Melbourne.

Westerman, R. L. (ed.). 1990. Soil testing and plant analysis. $3^{\text {rd }}$ ed. Soil Science Society. America, Inc., Madison, WI.

Winsor, G., and P. Adams. 1987. Diagnosis of mineral disorders in plants. Vol. 3. Glasshouse crops. Her majesty's Stationary Office. London.

Wright, M. J. (ed.). 1976. Plant adaptation to mineral stress in problem soils. Cornell Agr. Expt. Sta. Ithaca, New York. 
Table 1. Some adequacy-range Fe concentrations of plants from field culture ${ }^{z}$

\begin{tabular}{|l|c|c|}
\hline Plant & Plant part & Fe concentration \\
\hline Broccoli & leaves & 113 \\
\hline Pecan & leaves & $62-92$ \\
\hline clover & leaves & 93 \\
\hline grape & young leaves & $100-140$ \\
\hline rutabaga & leaves & 159 \\
\hline${ }^{2}$ values referenced in Barker and Pilbeam 2009. & & \\
\hline
\end{tabular}


Table 2. Some Fe-containing fertilizers

\begin{tabular}{|c|c|c|}
\hline Fertilizer & Formula or material & \% Fe \\
\hline Ferric sulfate & $\mathrm{FeSO}_{4} \cdot 7 \mathrm{H}_{2} \mathrm{O}$ & 20 \\
\hline Ferrous sulfate & $\mathrm{Fe}\left(\mathrm{SO}_{4}\right)_{3} \cdot 4 \mathrm{H}_{2} \mathrm{O}$ & 23 \\
\hline Ferric oxide & $\mathrm{Fe}_{2} \mathrm{O}_{3}$ & 70 \\
\hline Ferrous oxide & $\mathrm{FeO}$ & $5-15$ \\
\hline Iron chelates (several) & e. g., NaFeEDTA, NaFeDTPA & 10 \\
\hline Iron polyflavonoids & Complex & $5-8$ \\
\hline Iron Ligninsulfonates & Complex & \\
\hline Animal manures & Complex & $0.1-1.0$ \\
\hline
\end{tabular}

